\title{
Evaluation of ultrasound lung comets by hand-held echocardiography
}

\author{
G Bedetti ${ }^{1}$, L Gargani², A Corbisiero 3 , F Frassi², E Poggianti² and G Mottola*3
}

Address: ${ }^{1}$ Imola Hospital, Imola, Italy, ${ }^{2} \mathrm{CNR}$, Institute of Clinical Physiology, Pisa, Italy and ${ }^{3}$ Montevergine Clinic, Mercogliano, Italy

Email: G Bedetti - bedetti@osp.imola.it; L Gargani - gargani@ifc.cnr.it; A Corbisiero - bisturi78@yahoo.it; F Frassi - frassi@ifc.cnr.it; E Poggianti - poggianti@ifc.cnr.it; G Mottola* - mottola.gaetano@virgilio.it

* Corresponding author

Published: 31 August 2006

Cardiovascular Ultrasound 2006, 4:34 doi:10.1 186/1476-7|20-4-34
Received: 29 April 2006

Accepted: 3I August 2006

This article is available from: http://www.cardiovascularultrasound.com/content/4/I/34

(C) 2006 Bedetti et al; licensee BioMed Central Ltd.

This is an Open Access article distributed under the terms of the Creative Commons Attribution License (http://creativecommons.org/licenses/by/2.0), which permits unrestricted use, distribution, and reproduction in any medium, provided the original work is properly cited.

\begin{abstract}
Background: Ultrasound lung comets (ULCs) are a clinically useful sign of extravascular lung water. They require very limited technology (2 D-echo), and a short learning curve.

The aim of the present study is to compare ULCs information obtained by experienced echocardiologists using a full feature echocardiographic platform and by inexperienced sonographers using a hand-held echocardiography system.

Methods: 20 consecutive in-hospital patients underwent, within 15' and in random order, 2 ultrasound examinations for ULCs by 2 observers with different specific expertise and different technology: I) "high-tech veteran": ULCs assessment with full feature echocardiographic platform (HP Sonos 7500 Philips Medical Systems, Andover, MA, USA) by a trained echocardiologist, with $\geq 2$ years expertise in ULCs assessment and accredited by the European Association of Echocardiography; 2) and a "low-tech beginner": ULCs assessment with hand-held echocardiography (Optigo; Philips, Andover, MA) by an echocardiographer with very limited (30') dedicated training on ULCs assessment.

In each patient, ULC score was obtained by summing the number of comets from each of the scanning spaces in the anterior right and left hemithorax, from the second to the fifth intercostal space.

Results: There was a significant, tight correlation $(r=.958, p<0.001)$ between the 2 observations in the same patient by "high-tech veteran" and "low-tech beginner".

Conclusion: ULCs are equally reliable in the hands of highly experienced echocardiologists using full feature echocardiographic platforms and in the hands of absolute beginners with miniaturized, compact, and battery-equipped echocardiographic systems. From the technological and expertise viewpoint, ULCs are the "kindergarten" of echocardiography, ideally suited for bedside evaluation of patients with both known or suspected heart failure.
\end{abstract}

\section{Background}

The interstitial pulmonary oedema is a key parameter in the management of patients with chronic heart failure and an early warning sign of impending acute heart failure [1]. 
The objective diagnosis is traditionally based on chest radiographic findings which, when performed at the bedside, may be difficult to interpret, and may have weak correlations with extravascular lung water $[2,3]$. The lung is considered poorly accessible using ultrasound since air prevents the progression of the ultrasound beam with production of reverberation artefacts under the lung surface [4]. The "comet-tail image" is an echographic image detectable at bedside with ultrasound probes positioned over the chest [5]. This image consists of multiple comet tails fanning out from the lung surface originating from water-thickened interlobular septa. Functionally, they are a sign of distress of the alveolar-capillary membrane, often associated with reduced ejection fraction and increased pulmonary wedge pressure and they probably represent an ultrasonic equivalent of radiologic Kerley Blines [6]. These features make ultrasound lung comets (ULCs) an appealing simple clinically useful sign for detecting and quantifying extravascular lung water [7] in patients with known or suspected heart failure.

ULCs require very limited technology (2 D-echo, without Doppler functions or second harmonic option) and a short learning curve. Recently, hand-held echocardiography with compact, low cost, miniaturized, battery-driven ultrasound imaging system has became available [8].

The aim of our study is to compare the number of ULCs obtained by an experienced echocardiologist using a full feature echocardiographic platform and inexperienced sonographer using hand-held echocardiography and to evaluate the learning curve, the feasibility and the time needed for the echo lung examination.

\section{Methods}

\section{Patients population}

Twenty consecutive in-hospital patients (age $66 \pm 12$ years; 18 men), admitted to the cardio-pulmonary department of the Institute of Clinical Physiology, CNR in Pisa, have been included in the study.

\section{Echocardiography study}

All patients underwent, within $15^{\prime}$ and in random order, 2 ultrasound examinations for specific ULCs imaging by 2 observers utilizing different technology and with different expertise: 1) "high-tech veteran": ULCs assessment with a full feature echocardiographic platform (HP Sonos 7500 Philips Medical Systems, Andover, MA, USA) by a trained echocardiologist, with $\geq 2$ years expertise in ULCs assessment and accredited by European Association of Echocardiography; 2) "low-tech beginner": ULCs assessment with hand-held echocardiography (Optigo; Philips, Andover, MA) by an echocardiographer with very limited (30') dedicated training on ULCs assessment.

\section{Chest ultrasound}

The ULC was defined as a hyperechogenic, coherent bundle with narrow basis spreading from the transducer to the further border of the screen [9]. The ULC described here extends to the edge of the screen and arises only from the pleural line. The echographic examinations are performed with patients in the supine or near-supine position (Figure 1). Ultrasound scanning of the anterior and lateral chest is obtained on the right and left hemitorax, from the second to fourth (on the right side to the fifth) intercostal spaces, and from parasternal line to midaxillary line. In each intercostal space, the number of ULCs was recorded at the parasternal, midclavear, anterior and middle axillary lines [7]. The sum of the ULCs yielded a score denoting the extent of the extravascular fluid of the lung. Zero was defined as a complete absence of ULCs on the investigated area [9]. Observers were unaware of one another's results and ULCs measurements were independent of one another.
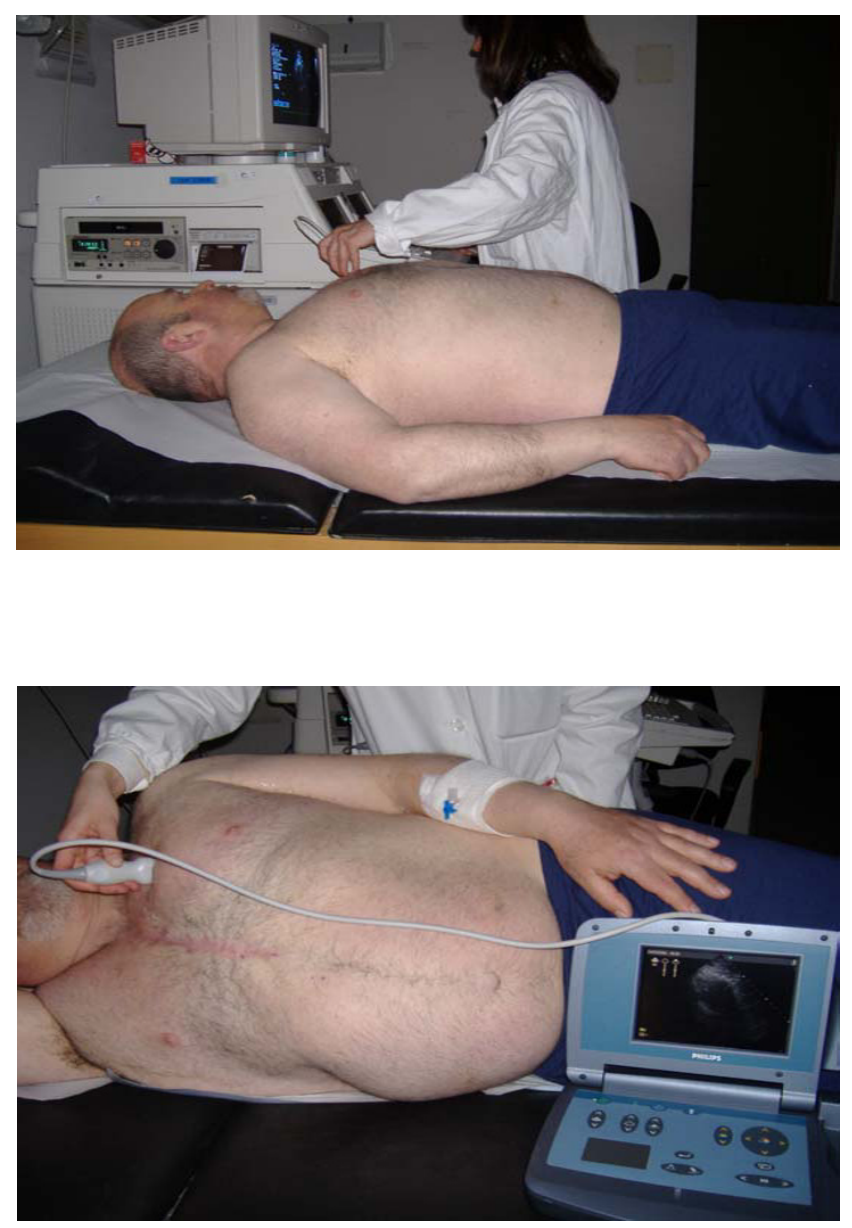

Figure I

Echographic examinations are performed with patients in the supine or near-supine position. 


\section{Statistics}

Data are expressed as mean \pm 1 standard deviation for continuous variables. The correlation between the measurements of the two observers was analyzed by two-tailed Pearson bivariate correlation. The statistical analyses of the data has been performed with SPSS for Windows (version 13.0, SPSS Inc., Chicago, Illinois). A p value $<0.05$ was considered to be significant.

\section{Results}

A total of 20 paired observations have been obtained for all the enrolled patients. The feasibility of the chest ultrasound examination for the diagnosis of ULCs was $100 \%$. The time needed for the echo lung examination was $<3$ minutes in all patients. A significant $(<5)$ number ULCs have been observed in 17 patients, while 3 patients showed a number of comets $<5$. The mean value of ULCs was $35.7 \pm 25.30$; and $34.2 \pm 26.8$ for the low tech beginner. Two examples of two representative patients with and without ULCs, are shown in Figures 2 and 3, respectively. The appearance and numbers was similar with the handheld echocardiography (Fig. 2 and 3, lower panels) and with the full feature echocardiographic platform (Figure 2 and 3, upper panels). There was a tight and highly significant correlation between the 2 observations in the same patient by the "high-tech veteran" and the "low-tech beginner" (Figure 4).

\section{Discussion}

ULCs are based on the principle that ultrasound is reflected by an interface between different acoustic impedance. In normal conditions, the ultrasound beam finds the lung air (ie, high impedance and no acoustic mismatch on its pathway through the chest) [6]. In the presence of extravascular lung water, the ultrasound beam finds sub-pleural interlobular septa thickened by oedema (ie, a low impedance structure surrounded by air and with a high acoustic mismatch). The reflection of the beam creates a phenomenon of reverberation. The result is a wedge - shaped signal with a narrow origin in the near field of the image [9]. We have found that ULCs are equally reliable in the hands of highly experienced echocardiologist using expensive and complex technology and in the hands of absolute beginners with hand-held echocardiography. ULCs are easy both to obtain and to measure (learning curve of $<10$ examinations, 30 minutes) and fast to perform (<3 minutes), require very limited technology, even without a second harmonic or Doppler and are not restricted by cardiac acoustic window limitations or patient decubitus. The feasibility was $100 \%$.

\section{Clinical implications}

Pulmonary congestion resulting from elevated left atrial and left ventricular filling pressures appears before the onset of patient symptoms, and may provide an early
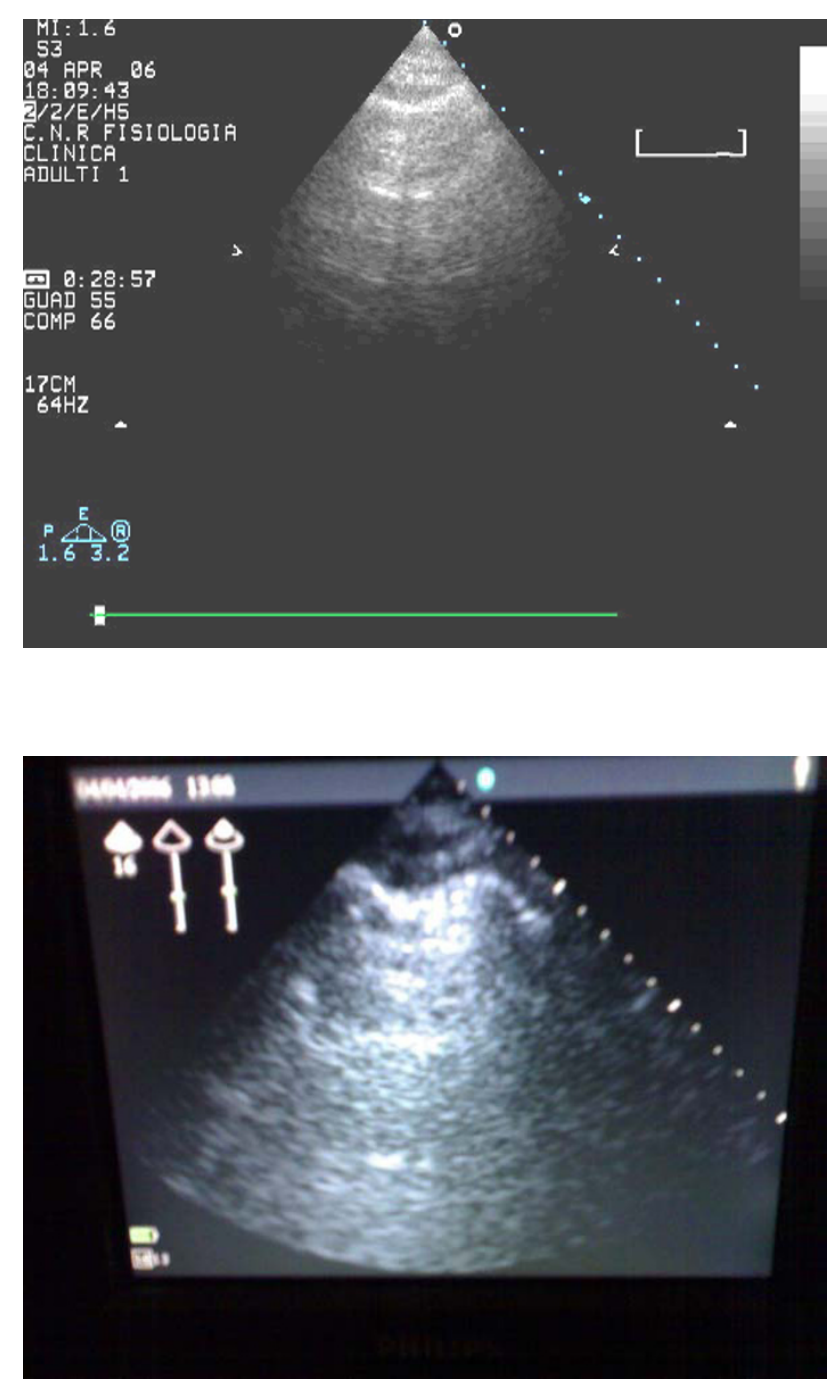

Figure 2

Example of patients without ULCs.

warning of impending heart failure. The possibility that sufficiently accurate techniques could be used to detect pulmonary oedema even before it becomes clinically apparent "is so inherently attractive that the effort to develop and validate such techniques still continues" [10].

The standard chest radiograph remains the best screening test for the detection of pulmonary oedema, but it requires radiology facilities, specific reading expertise, it uses ionising energy, and poses a significant logistic burden. ULCs assessment provides an appealing simple, nonradiologic and low cost bedside alternative to available methods and it appears to be reasonably well correlated with extra-vascular lung water assessed by chest radiography [7] and other highly complex methods such as com- 

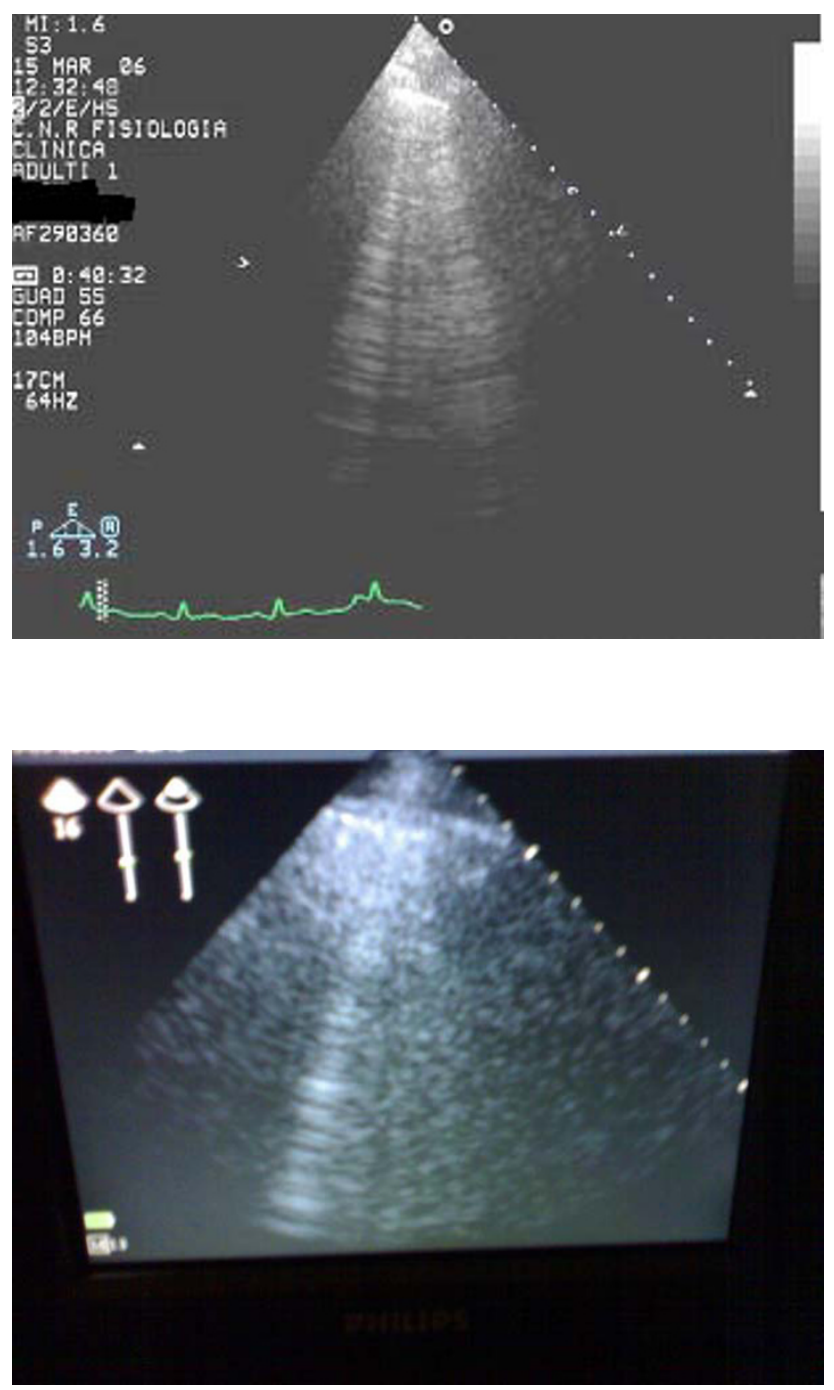

Figure 3

Example of patients with ULCs.

puterized tomography and thermodiluition techniques [11]. It is theoretically appealing for detecting and quantifying extravascular lung water, a key parameter in the serial evaluation of the cardiologic patient with heart failure [13]. It seems attractive for complement conventional Doppler-echocardiography in the fast evaluation of patients with known or suspected heart failure and dyspnoea as a presenting symptom in the emergency department (for the differential diagnosis of dyspnoea), inhospital management (for serial evaluations in the same patient and for tailoring diuretic therapy), home care (with hand-held echocardiography), and stress echocardiography lab (as a sign of acute pulmonary congestion during stress) [14].

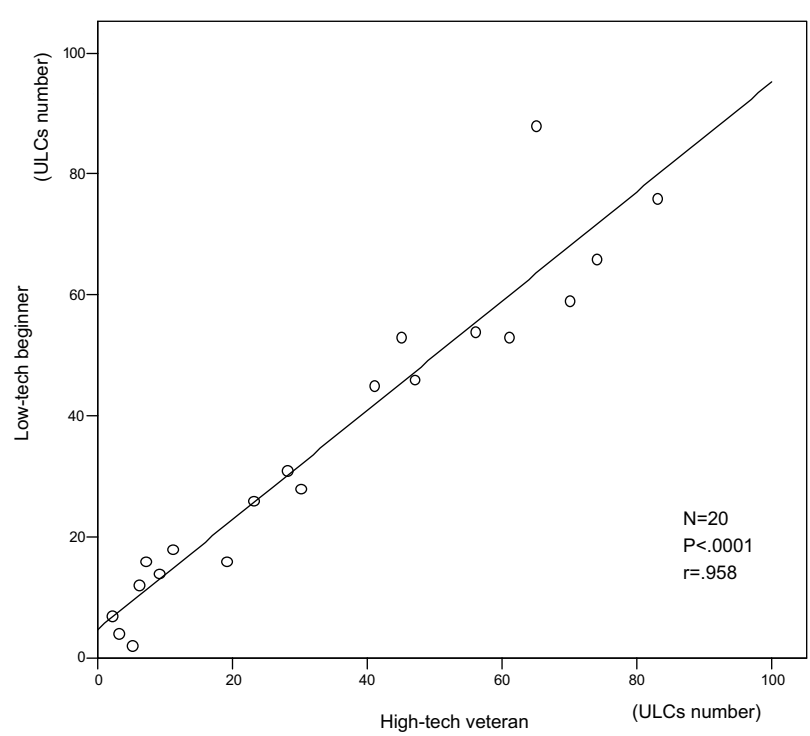

Figure 4

Graph showing the significant correlation between the 2 observations in the same patient by the "high-tech veteran" and the "low-tech beginner".

\section{Conclusion}

Since the qualitative nature of the interpretation is the recognized Achilles hell of echocardiographic techniques $[15,16]$, it is especially reassuring that both the presence and extent of ULCs can be obtained with optimal precision, with very limited training, and with very basic and unsophisticated technology. From the technological and expertise viewpoint, ULCs are the "kindergarten" of echocardiography, ideally suited for bedside evaluation of patients with both known or suspected heart failure.

\section{Abbreviations}

ULCs = Ultrasound lung comets

\section{Competing interests}

The author(s) declare that they have no competing interests.

\section{Authors' contributions}

LG, GB and EP performed all of the ULCs assessments. AC and FF performed all the statistical analysis of the study. GM participated in the study design and coordination an helped to draft the manuscript. All authors read and approved the final manuscript.

\section{References}

I. Swedberg K, Cleland J, Dargie H, Drexler H, Follath F, Komajda M, Tavazzi L, Smiseth OA, Gavazzi A, Haverich A, Hoes A, Jaarsma T, Korewicki J, Levy S, Linde C, Lopez-Sendon JL, Nieminen MS, Pierard L, Remme WJ: Task Force for the Diagnosis and Treatment of Chronic Heart Failure of the European Society of Cardiology. Guidelines for the diagnosis and treatment of chronic 
heart failure: executive summary (update 2005): The Task Force for the Diagnosis and Treatment of Chronic Heart Failure of the European Society of Cardiology. Eur Heart J 2005,

2. Halperin B, Feeley T, Mihm F, et al:: Evaluation of the portable chest roentgenogram for quantitating extravascular lung water in critically ill adults. Chest 1985, 88:649-652.

3. Eisenberg PR, Hansbrough JR, Anderson D, et al.: A prospective study of lung water measurements during patient management in an intensive care unit. Am Rev Respir Dis 1987, 136:662-668.

4. Targhetta R, Chavagneaux R, Bourgeois JM, et al:: Sonographic approach to diagnosing pulmonary consolidation. J Ultrasound Med 1992, I I:667-672.

5. Lichtenstein D, Meziere G, Biderman P, Gepner A, Barre O: The comet-tail artifact. An ultrasound sign of alveolar-interstitial syndrome. Am J Respir Crit Care Med 1997, 1 56:1640-1646.

6. Picano E, Frassi F, Agricola E, Gligorova S, Gargani L, Mottola G: Ultrasound Lung Comets: A Clinically Useful Sign of Extravascular Lung Water. I Am Soc Echocardiogr 2006, 19:139-146.

7. Jambrik Z, Monti S, Coppola V, Agricola E, Mottola G, Miniati M, Picano $E$ : Usefulness of ultrasound lung comets as a nonradiologic sign of extravascular lung water. Am J Cardiol 2004, 93: $1265-1270$

8. Giannotti G, Mondillo S, Galderisi M, Barbati R, Zaca V, Ballo P, Agricola $E$, Guerrini $F$ : Hand-held echocardiography: added value in clinical cardiological assessment. Cardiovasc Ultrasound 2005, 3:7.

9. Lichtenstein D, Meziere G: A lung ultrasound sign allowing bedside distinction between pulmonary edema and chronic obstructive pulmonary disease: the comet-tail artifact. Intensive Care Med 1998, 24:1331-1334.

10. Lange NR, Schuster DP: The measurement of lung water. Crit Care 1999, 3:RI9-R24.

11. Agricola E, Bove T, Oppizzi M, Marino G, Zangrillo A, Marginato A, Picano E: "Ultrasound comet-tail images": a marker of pulmonary edema. Chest 2005, I 27:1690-1695.

12. Gheorghiade M, Zannad F: Modern management of acute heart failure syndromes. Eur Heart J 2005, 7(suppl B):B3-B7.

13. Givertz MM, Colucci WS, Braunwald E: Clinical aspects of heart failure: high-output failure, pulmonary edema. In Heart Disease 6th edition. Edited by: Braunwald E, Zipes DS, Libby P. Philadelphia, PA: WB Saunders; 200I:545-546.

14. Agricola E, Picano E, Oppizzi M, Pisani M, Meris A, Fragasso G, Margonato $A$ : Assessment of stress-induced pulmonary interstitial edema by chest ultrasound during exercise echocardiography and its correlation with left ventricular function. J Am Soc Echocardiography 2006, 19:457-463.

15. Douglas PS, Foster E, Gorcsan J, Lewis JF, Pearlman AS, Rychik J, Salcedo EE, Seward JB, Stevenson JB, Thys DM, Weitz HH, Zoghbi WA: ACC/AHA clinical competence statement on echocardiography. J Am Coll Cardiol 2003, 41:687-708.

16. Picano E, Lattanzi F, Orlandini A, Marini C, L'Abbate A: Stress echocardiography and the human factor: the importance of being export. J Am Coll Cardiol 1991, 17:666-669.
Publish with Biomed Central and every scientist can read your work free of charge

"BioMed Central will be the most significant development for disseminating the results of biomedical research in our lifetime. "

Sir Paul Nurse, Cancer Research UK

Your research papers will be:

- available free of charge to the entire biomedical community

- peer reviewed and published immediately upon acceptance

- cited in PubMed and archived on PubMed Central

- yours - you keep the copyright
BioMedcentral 